\title{
Successful treatment of advanced alveolar soft part sarcoma with camrelizumab combined with apatinib: a case report
}

\author{
Zhen $\mathrm{Xu}^{1}$, Yong Zhang ${ }^{2}$, Yong-Hua Yu ${ }^{2}$ \\ ${ }^{1}$ Cancer Hospital of Shandong First Medical University, Shandong Cancer Hospital and Institute,Jinan, China; ${ }^{2}$ Department of Abdominal Radiation \\ Oncology Ward 2, Cancer Hospital of Shandong First Medical University, Shandong Cancer Hospital and Institute, Jinan, China \\ Correspondence to: Yong-Hua Yu. Department of Abdominal Radiation Oncology Ward 2, Cancer Hospital of Shandong First Medical University, \\ Shandong Cancer Hospital and Institute, No. 440 Ji Yan Road, Jinan 250117, China. Email: sdwufx@163.com.
}

\begin{abstract}
Alveolar soft part sarcoma (ASPS) is a rare and highly malignant mesenchymal tumor that primarily affects adolescents and young adults. ASPS is characterized by a slow growth rate, high metastatic potential, and resistance to conventional therapies. The emergence of immune checkpoint inhibitors (ICIs) has revolutionized the treatment of advanced malignancies, improving the objective response rate (ORR) and prolonging patient survival. The combination of immunotherapy with targeted therapies can overcome resistance to treatment with ICIs alone. Although substantial progress has been made in various solid tumors, the clinical relevance of ICIs, used alone or in combination with other therapies, in patients with ASPS remains unclear. This is a case report of a 32-year-old man who was diagnosed with advanced ASPS. After 8 months of anlotinib treatment, the patient's disease progressed and new cerebellar metastases were detected. Radiotherapy was administered in addition to camrelizumab combined with apatinib to treat the brain metastases. The patient achieved partial remission (46\%) after 3 months of treatment and did not present any severe side effects. This is the first reported case of the successful treatment of advanced ASPS with camrelizumab combined with apatinib. This case supports the use of a novel treatment regimen for patients with inoperable ASPS or ASPS that is resistant to conventional therapies.
\end{abstract}

Keywords: Alveolar soft part sarcoma (ASPS); immunotherapy; camrelizumab

Submitted Oct 12, 2020. Accepted for publication Jan 21, 2021.

doi: 10.21037/apm-20-2275

View this article at: http://dx.doi.org/10.21037/apm-20-2275

\section{Introduction}

Alveolar soft part sarcoma (ASPS) was first described by Christopherson and Stewart in 1952 as a rare type of soft tissue malignancy (1). ASPS comprises only $0.5-1.0 \%$ of all soft tissue sarcomas (2), and predominantly affects young individuals aged between 15 and 35 years old. In children, ASPS primarily affects the head and neck (2,3), while in adults it typically occurs in the deep soft tissues of the limbs and body trunk, especially in the upper and lower extremities (2). In contrast to other sarcomas, ASPS is characterized by inert growth and a high incidence of distant metastasis (4). In fact, the majority of ASPS patients present with distant metastases at the time of diagnosis, with the lungs being the most common metastatic site (42\%), followed by the bones (19\%), brain (15\%), and lymph nodes (7\%) (2).

The most effective treatment for patients with earlystage ASPS is radical surgical excision of the primary tumor (2). However, the therapeutic options for patients with advanced disease are limited by the resistance of ASPS to radiotherapy and chemotherapy $(2,5)$. In fact, conventional chemotherapy has a complete or partial response rate of less than $10 \%$ (2). As a consequence, the prognosis of patients with advanced or metastatic ASPS is extremely poor $(5,6)$. Therefore, the development of novel and more effective therapeutic methods for the treatment of ASPS is of high clinical importance.

The tyrosine kinase inhibitor (TKI) apatinib has been 

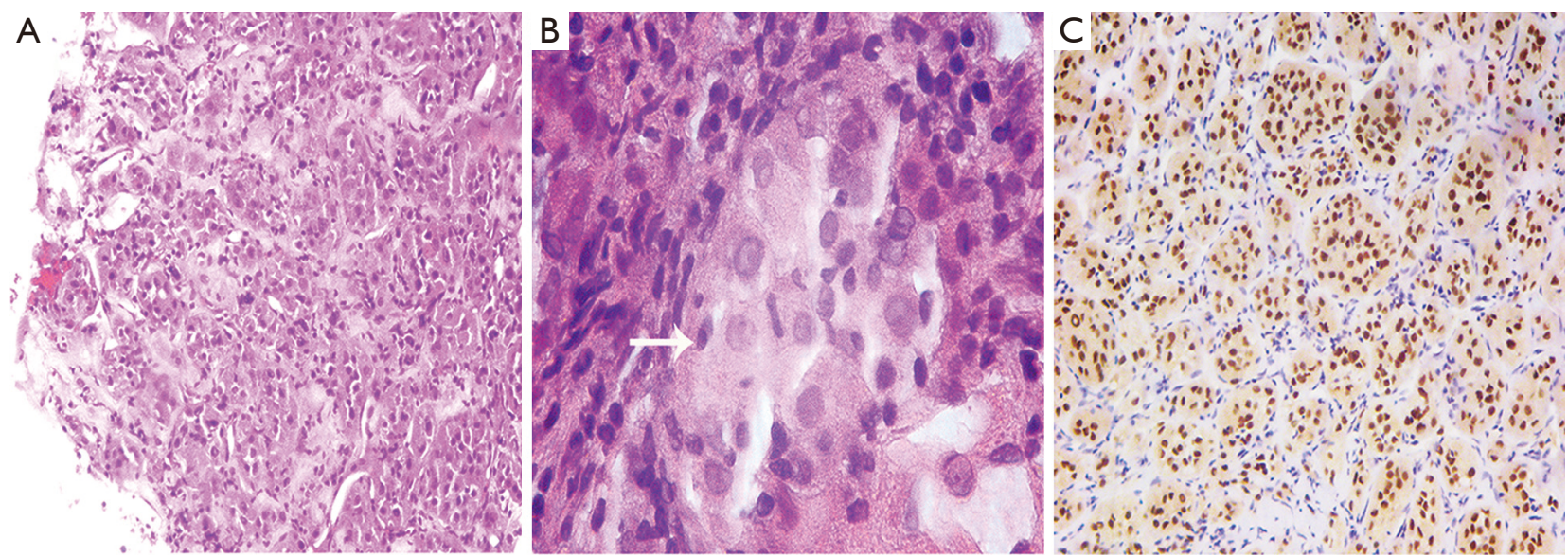

Figure 1 Alveolar soft part sarcoma in a 32-year-old male. (A) Hematoxylin and eosin (H\&E) staining showing a nested growth pattern in tumor cells (magnification $\times 100$ ). (B) Typical periodic acid-Schiff (PAS)-positive particles were observed in the cytoplasm of neoplastic cells (white arrow). The cell nucleoli were large and eccentric (H\&E; magnification $\times 400)$. (C) Representative immunohistochemical staining (IHC) image showing strong nuclear TFE3 expression in alveolar soft part sarcoma (ASPS) cells (IHC; magnification $\times 100$ ).

shown to exert potent anti- angiogenic and anti-tumor effects $(7,8)$. Moreover, camrelizumab, a newly developed humanized programmed cell death 1 (PD-1) monoclonal antibody, binds to PD-1 with high-affinity, blocking the PD-1 pathway on $T$ cells, thereby unleashing a cascade of anti-tumor immune responses $(6,9,10)$. It has been reported that the combination of these two drugs exerts a synergistic effect while maintaining a favorable safety profile (8).

This is a case report of a 32-year-old male with advanced ASPS and multiple organ metastases who showed a strong response to treatment with the combination of camrelizumab plus apatinib. Follow-up imaging after six treatment cycles revealed that both the primary tumor and metastatic lesions had regressed. The patient's vital signs were stable, and his quality of life was improved.

We present the following article in accordance with the CARE reporting checklist (available at http://dx.doi. org/10.21037/apm-20-2275).

\section{Case presentation}

A 32 -year-old male presented to the hospital with hemoptysis in July, 2018. Computed tomography (CT) examination revealed multiple bilateral lung metastases, as well as a pancreatic lesion (size: $2.8 \mathrm{~cm} \times 2.9 \mathrm{~cm} \times 2.4 \mathrm{~cm}$ ) which was biopsied. Patient has former cigarette smoking history of at least 15 years. No family history was identified. Microscopically, a nested growth pattern was observed, in which the diffusely distributed tumor cells were uniform in size and shape, and surrounded by fibrous blood vessels (Figure 1A). Typical periodic acid-Schiff (PAS)positive particles were observed in the cytoplasm, and the cell nucleoli were large and eccentric (Figure 1B). Immunohistochemical staining (IHC) indicated strong positive expression of nuclear TFE3 (Figure 1C).

Since ASPS very rarely develops in the pancreas, investigations were conducted to determine the location of the primary tumor. A positron emission tomography (PET-CT) scan revealed that the primary tumor was in the right thigh (size: $4.1 \mathrm{~cm} \times 4.4 \mathrm{~cm}$; maximum standardized uptake value: 8.9 ; Figure $2 A$ ). Hence, the patient was diagnosed with stage IV ASPS originating from the right femur [clinical stage T1N0M1 as per the American Joint Committee on Cancer (AJCC) staging system, 8th edition]. Since surgery is not recommended for advanced ASPS patients, the patient was prescribed the TKI anlotinib (12 mg, from day 1 to day 14, repeated every 21 days). After 8 months of anlotinib treatment, the patient developed grade 1 liver damage, and new metastases were detected on the right cerebellum (size: $2.0 \mathrm{~cm} \times 1.5 \mathrm{~cm}$ ). As a result of this, the administration of anlotinib was discontinued.

The patient's brain metastases were treated with radiotherapy, using a total dose of $60 \mathrm{~Gy}$, given at 2-Gy fractions, five times per week. The patient also underwent six cycles of a different TKI, apatinib (450 mg, once daily), combined with camrelizumab (200 mg, every 2 weeks). After 3 months of treatment, the patient achieved partial remission ( $46 \%$ from baseline; Figure 2B,C,D,E) based on the Response 

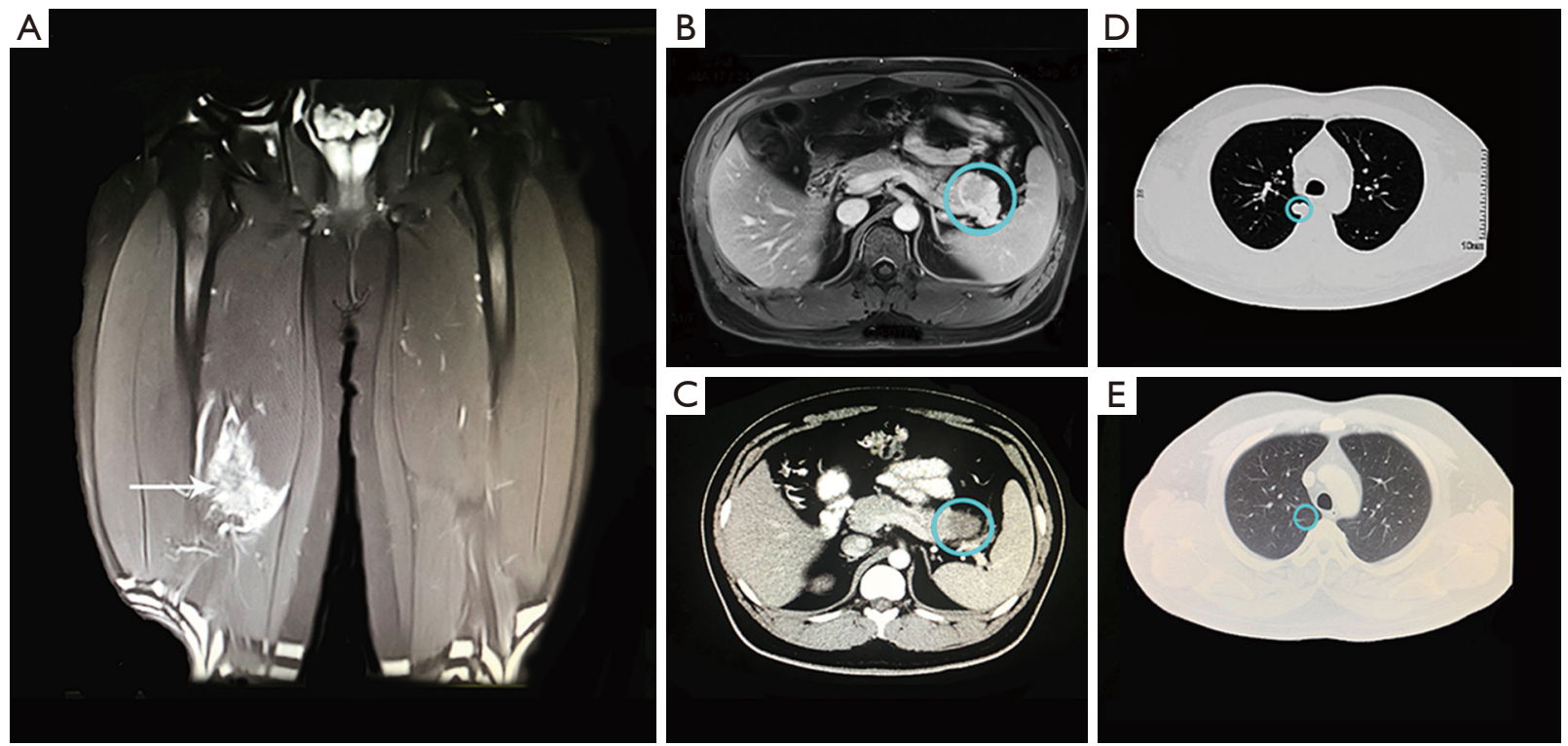

Figure 2 Imaging evaluation of apatinib combined with camrelizumab antitumor activity. (A) T2 arterial phase magnetic resonance imaging showing the primary alveolar soft part sarcoma (ASPS) tumor in the right anterior thigh (white arrow). (B) T2-weighted MRI showing the pancreatic lesion (blue circle). (C) Contrast-enhanced computed tomography (CT) scan showing regression of the pancreatic lesion 4 months after the combination therapy. (D) Right lung metastases (blue circle) before treatment. (E) Contrast-enhanced CT scan showing tumor regression in the lung after six cycles of combination therapy.

Evaluation Criteria in Solid Tumors (RECIST) version 1.1. After 6 months of treatment, the tumor regression continued with a $69 \%$ decrease from baseline. During the course of treatment, the patient experienced grade 1 bone marrow suppression (neutrophil granulocyte count was $0.63 \times 10^{9} / \mathrm{L}$ in the first cycle of treatment), which improved after symptomatic treatment. A follow-up was conducted every 3 months, including physical examination, enhanced CT of the chest, abdomen and lower extremities, enhanced MR of the brain and serum tumor markers. The patient is still receiving treatment and to date we have not observed treatment related side effects. Followed up to October 2020, the patient showed sustain partial remission for 10 months, and his life satisfaction is improved (Figure 3).

Written informed consent was obtained from the patient for publication of this study and any accompanying images. All procedures performed in studies involving human participants were in accordance with the ethical standards of the institutional and/or national research committee(s) and with the Helsinki Declaration (as revised in 2013).

\section{Discussion}

ASPS is an extremely rare and highly malignant soft tissue tumor. It is characterized by a relatively slow growth rate, high metastatic potential, and a high likelihood of recurrence (11). Typically, ASPS is insidious in its onset, commonly manifesting as a painless mass (11). Often, patients initially present with hemoptysis or headaches. The lack of distinct symptoms hampers early detection, resulting in a high frequency of missed diagnosis and misdiagnosis. The blood-rich nature of ASPSs often leads to hematogenous spread and subsequent distant metastases in the early stages of the disease (6). In fact, pulmonary or brain metastases are detected during the initial diagnosis in $33 \%$ of ASPS patients (11). The vast majority of patients diagnosed with pulmonary metastasis also develop metastases in other distant organs (12). Pathological diagnosis remains the gold standard for ASPS. The histological features of ASPS are unique. The polygonal tumor cells are separated by thick fibrous septa, forming uniform-sized lobules (13). The tumor cells have eosinophilic cytoplasm, which contains diamond-shaped or needle-like PAS crystals (14). Additionally, most ASPSs are positive for nuclear TFE3 expression (13).

Previous cytogenetic studies have demonstrated the involvement of chromosomal abnormalities in ASPS (15). Notably, the unbalanced translocation $\operatorname{der}(5) \mathrm{t}(\mathrm{X} ; 17)$ 


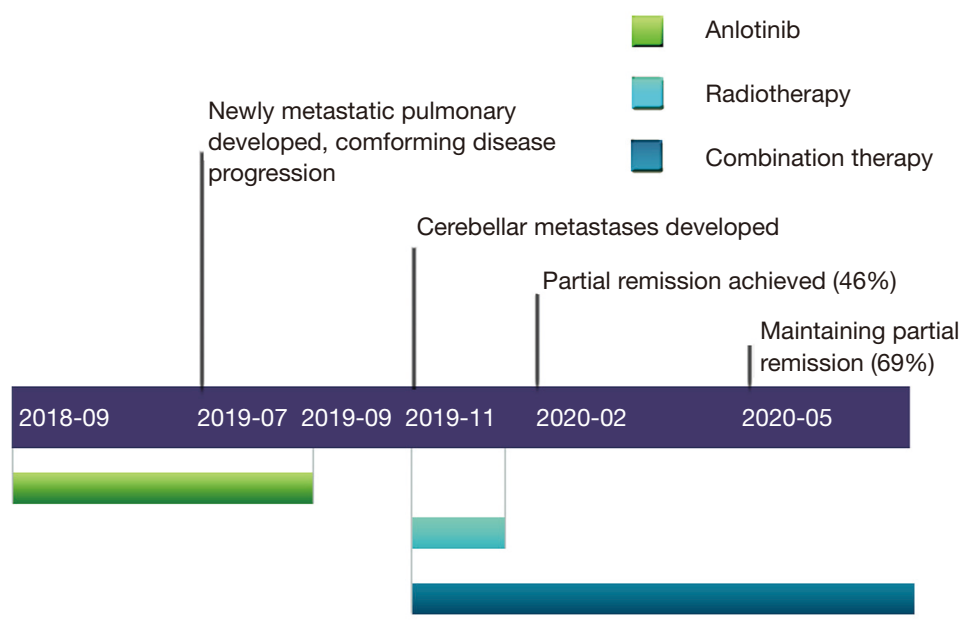

Figure 3 Treatment process timeline, illustrating the application of drugs and the state of disease during treatment.

(p11.2; 25 ) is frequently detected in ASPS patients, and results in the transfusion of the TFE3 gene with ASPL (15). The transcripts expressed by the ASPL-TFE3 fusion gene can induce aberrant cell proliferation along with the secretion of angiogenesis-promoting factors, such as neurite growth-promoting factor 2 (NEGF2) and Jagged-1 (JAG1). These factors contribute to the high vascularization and metastatic potential of ASPS $(16,17)$.

Although ASPS is a relatively inert sarcoma, clinical evidence has shown that it is resistant to radiotherapy and chemotherapy (11). Despite the use of anti-angiogenic agents, such as apatinib, bevacizumab, and sunitinib, in the treatment of metastatic ASPS, tumor recurrence is inevitable (14). Ultimately, the prognosis of ASPS is poor, and patients often die from complications arising from metastases to vital organs. The overall 5 -year survival rate of patients with ASPS ranges from $38-88 \%$ (14). For patients without distant metastases, the 5 -year survival rate is $60-71 \%$, while metastatic patients have a 5 -year survival rate of only $10 \%(18,19)$.

Immunotherapy has emerged as a promising therapeutic approach for several malignancies. Notably, antibodies targeting PD-1 and its ligand, PD-L1, have improved the survival rates and quality of life of cancer patients (5). PD-1 is a transmembrane protein that is expressed on the surface of activated immune cells. As PD-1 has a role in mediating inhibitory signals, blocking the interaction between PD-1 and PD-L1 re-activates lymphocytes and restores antitumor immune responses $(20,21)$. CTLA-4 blockers can activate tumor-specific $\mathrm{T}$ cells by blocking the binding of B7 to CTLA-4 molecules and enhance the anti-tumor immune response (22). Early studies have confirmed that PD-1/PD-L1 more efficient, and the immunosuppressive effect is longer, safer and more reliable (22-24). According to reports in the literature, ASPS PD-1 has a single-agent effective rate of $42-50 \%(5,25)$. In a study by Groisberg et al., four ASPS patients were treated with immunotherapy. Partial remission was achieved in $50 \%$ of the patients while the other $50 \%$ exhibited stable disease (5). Despite the limited number of patients in the latter study, the response rates were promising. The anti-PD-1monoclonal antibody camrelizumab has been approved by the State Drug Administration of China for the treatment of recurrent or refractory classical Hodgkin lymphoma after secondline chemotherapy (26). Despite this, the overall efficacy of PD-1/PD-L1 blockade in the treatment of sarcoma is still inadequate. According to SARC028, a phase II clinical study, the objective response rate (ORR) of immunotherapy in soft tissue sarcoma patients was 19\% (27). In the case report presented here, combination treatment with camrelizumab and apatinib resulted in significant regression of the malignant lesions, representing a partial response. Current clinical studies had confirmed the combination treatment of unresectable ASPS already achieved higher response rate, disease control rate, and longer PFS than before. However, the currently researches are mostly case reports, it is insufficient to screen out patient characteristics that benefit from combination therapy of camrelizumab with apatinib. Therefore, large randomized controlled trial should be conducted to examine the potential benefits of 
Table 1 Clinical Trials for SHR-1210 combined with apatinib for the treatment of other diseases

\begin{tabular}{|c|c|c|c|c|c|}
\hline Author & Disease & Interventions & Efficacy & $\begin{array}{l}\text { PD-L1 expression status and } \\
\text { response }\end{array}$ & Adverse event \\
\hline $\begin{array}{l}\text { Xu J } \\
\text { et al. (8) }\end{array}$ & $\begin{array}{l}\text { Advanced } \\
\text { hepatocellular } \\
\text { carcinoma, } \\
\text { gastric or } \\
\text { esophagogastric } \\
\text { junction cancer }\end{array}$ & $\begin{array}{l}\text { SHR-1210 } 200 \mathrm{mg} \\
\text { every } 2 \text { weeks and } \\
\text { apatinib } 125-500 \mathrm{mg} \\
\text { once daily }\end{array}$ & $\begin{array}{l}\text { Hepatocellular } \\
\text { carcinoma PR 50\%, } \\
\text { ORR 50\%, median PFS } \\
5.8 \text { months; GC/EGJC } \\
\text { ORR } 17.4 \% \text {, median PFS } \\
2.9 \text { months }\end{array}$ & $\begin{array}{l}\text { CTCs PD-L1 expression } \\
\geq 20 \% 82.9 \%,<20 \% 12.2 \% \text {; } \\
\text { CTCs PD-L1 expression } \\
\geq 20 \% \text { had a longer median } \\
\text { PFS ( } 6.1 \text { vs. } 2.9 \text { months) and } \\
\text { median OS (NR vs. } \\
8.9 \text { months) }\end{array}$ & $\begin{array}{l}\text { Grade } 3 \text { or } 4 \text { AEs } 60.6 \% \text {, } \\
\text { mostly hypertension } \\
15.2 \% \text {, increased } \\
\text { aspartate } \\
\text { aminotransferase } 15.2 \%\end{array}$ \\
\hline $\begin{array}{l}\text { Lan C } \\
\text { et al. (29) }\end{array}$ & $\begin{array}{l}\text { Advanced } \\
\text { cervical cancer }\end{array}$ & $\begin{array}{l}\text { SHR-1210 } 200 \mathrm{mg} \\
\text { every } 2 \text { weeks and } \\
\text { apatinib } 250 \mathrm{mg} \\
\text { once per day }\end{array}$ & $\begin{array}{l}\text { ORR } 55.6 \% \text {, CR } 4.4 \% \text {, } \\
\text { PR } 51.1 \% \text {, median } \\
\text { PFS } 8.8 \text { months }\end{array}$ & $\begin{array}{l}\text { PD-L1 positive } 66.7 \% \text {, } \\
\text { PD-L1 negative } 22.2 \%\end{array}$ & $\begin{array}{l}\text { Grade } 3 \text { or } 4 \text { AEs } 71.1 \% \text {, } \\
\text { mostly hypertension } \\
24.4 \% \text {, anemia } 20.0 \% \text {, } \\
\text { fatigue } 15.6 \%\end{array}$ \\
\hline $\begin{array}{l}\text { Fan } Y \\
\text { et al. (31) }\end{array}$ & $\begin{array}{l}\text { Extensive-stage } \\
\text { small-cell lung } \\
\text { cancer }\end{array}$ & $\begin{array}{l}\text { SHR-1210 } 200 \mathrm{mg} \\
\text { every } 2 \text { weeks plus } \\
\text { apatinib } 375 \mathrm{mg} \\
\text { once daily }\end{array}$ & $\begin{array}{l}\text { ORR } 34.0 \% \text {, median } \\
\text { PFS } 3.6 \text { months, } \\
\text { OS } 8.4 \text { months }\end{array}$ & $\begin{array}{l}\text { PD-L1 expression } \geq 1 \% \\
23.4 \% \text {, PDL1 }<1 \% 70.2 \% \\
\text { PD-L1 expression } \geq 1 \% \\
\text { had a longer ORR }(45.5 \% \text { : } \\
33.3 \%)\end{array}$ & $\begin{array}{l}\text { Grade } 3 \text { or } 4 \text { AEs } 72.9 \% \text {, } \\
\text { mostly hypertension } \\
25.4 \% \text {, decreased } \\
\text { platelet count } 13.6 \% \text {, } \\
\text { hand-foot syndrome } \\
13.6 \%\end{array}$ \\
\hline $\begin{array}{l}\text { Xu J } \\
\text { et al. (32) }\end{array}$ & $\begin{array}{l}\text { Advanced } \\
\text { hepatocellular } \\
\text { carcinoma }\end{array}$ & $\begin{array}{l}\text { SHR-1210 } 200 \mathrm{mg} \\
\text { (for bodyweight } \\
\geq 50 \mathrm{~kg} \text { ) or } 3 \mathrm{mg} / \mathrm{kg} \\
\text { (for bodyweight } \\
<50 \mathrm{~kg} \text { ) every } 2 \text { weeks } \\
\text { plus oral apatinib } \\
250 \text { mg daily }\end{array}$ & $\begin{array}{l}\text { The first-line ORR } 34.3 \% \\
\text { median PFS } 5.7 \text { months; } \\
\text { the second-line } \\
\text { ORR } 22.5 \% \text { median } \\
\text { PFS } 5.5 \text { months }\end{array}$ & Not mentioned & $\begin{array}{l}\text { Grade } 3 \text { or } 4 \text { AEs } 77.4 \% \text {, } \\
\text { mostly hypertension } \\
34.2 \% \text {, increase dgamma- } \\
\text { glutamyltransferase } \\
11.6 \% \text {, neutropenia } 11.1 \%\end{array}$ \\
\hline
\end{tabular}

PR, partial response; CR, complete response; ORR, objective response rate; OS, overall survival; PFS, progression-free survival; PD-L1, programmed death-ligand 1; NR not reached; AEs, adverse effects; CTCs, circulating tumor cells

PD-1/PD-L1 blockade, either alone or in combination with other therapies, in the treatment of patients with ASPS.

Although immunotherapy has lower toxicity than traditional chemotherapy, its long-term adverse events (AEs) still cannot be ignored. The long-term AEs are mainly endocrine toxicity. The most common ones are hypophysitis and hypopituitarism (incidence rate 1-10\%) (23), followed by gastrointestinal side effects, mostly colitis (grade $\geq 3$ $1-5 \%$ ), ileus, intestinal perforation (28). Compared with CTLA-4, the AEs of PD-1/PD-L1 require longterm monitoring (22). Blood routine examination, liver function, biochemistry index, and thyroid function were recommended every $6-12$ weeks within 6 months after the end of treatment. Other hormone levels, such as corticotropin, cortisol should be tested when the patient has fatigue or non-specific symptoms (28). Follow-up frequency should be increased according to individual reactions and AEs.

A number of previous clinical studies have explored the use of SHR-1210 combined with apatinib for digestive system carcinoma, advanced cervical cancer, and extensive-stage small-cell lung cancer $(8,29-32)$ (Table 1 ). Studies by $\mathrm{Xu} \mathrm{J}, \mathrm{Xu}$ $\mathrm{JM}$ and others have confirmed that the combination of the two drugs can improve the ORR and long survival of patients with advanced hepatocellular carcinoma $(8,32)$. However, in other studies, the combination of the two drugs for progressive colon cancer, gastric cancer and gastroesophageal junction tumors is not exhaustive $(8,32)$. Patients with PDL1 expression are more likely to benefit from combination treatment, but the relationship between PDL1 expression 
level and efficacy is still uncertain $(8,23)$. According to the research of $\mathrm{Xu} \mathrm{J}$ and Lan $\mathrm{C}, \mathrm{PD}-\mathrm{L} 1$ tumor cell-positive patients are associated with longer PFS, but ORR does not benefit (29,32). Another study has demonstrated that patients with PDL1 positive had better ORR than patients with PDL1 negative (45.5\%: $33.3 \%$ ) (31). In addition to efficacy, safety is also an important factor to be considered in the treatment process. Grade 3 or 4 AEs were observed $60-90 \%$, mostly hypertension $15.2-34.2 \%$, hepohepatia 11.6-15.2\%, marrow suppression et al. (8,26,30-32). Compared with SHR-1210 monotherapy, the skin capillary hyperplasia symptoms, which is the most common side effect of SHR-1210, were lower than before (67-97\%: $3-28.9 \%)(8,29-33)$. The mechanism may be related to that apatinib inhibits the VEGFR2 receptor related to vascular endothelial proliferation and blocks angiogenesis (8). Considering the efficacy and tolerability, the dose of SHR-1210 $200 \mathrm{mg}$ every 2 weeks and apatinib $250 \mathrm{mg}$ once per day are recommended.

It is worth noting that the efficacy of immunotherapy is positively correlated with the tumor mutation burden (21). ASPS, as a single-type mutant soft tissue tumor, is more sensitive to immunotherapy. However, previous studies observed that PD-L1 was only expressed in 0-2\% of ASPS cells and that the infiltrating immune cells did not express PD-1 $(5,6,29)$. It is possible that the sensitivity of ASPS to immunotherapy is related to the expression of TFE3, which is involved in the activation of the immune system (16). Future investigations are warranted to provide further insights into the mechanisms underlying the responses of ASPS to immunotherapy.

Our patient is a young male with a history of smoking for 15 years. He was given the standard treatment of SHR-1210 $200 \mathrm{mg}$ every 2 weeks and apatinib $250 \mathrm{mg}$ once daily. In the 3rd and 6th months after treatment, the patient's tumor burden was significantly reduced decrease from baseline $(46 \%, 69 \%)$. Previous studies have paid more attention to the mechanism of targeted therapy and achieved curative effects. Our patient admitted drug resistance after using anlotinib, apatinib combined with camrelizumab was selected and achieved significant efficacy.

\section{Conclusions}

This case study reported an extremely rare ASPS case with metastases in multiple distant organs, including the pancreas. To the best of our knowledge, this case represents the first report of the successful treatment of advanced
ASPS with the combination of camrelizumab plus apatinib. The patient's condition improved significantly after treatment, and no adverse side effects greater than grade 3 were observed, thus confirming the favorable safety and efficacy profiles of this treatment regimen. Therefore, the efficacy of this combination treatment in ASPS patients who are resistant to conventional therapies should be further evaluated in large cohort studies.

\section{Acknowledgments}

Funding: None.

\section{Footnote}

Reporting Checklist: The authors have completed the CARE reporting checklist. Available at http://dx.doi.org/10.21037/ apm-20-2275

Conflicts of Interest: All authors have completed the ICMJE uniform disclosure form (available at http://dx.doi. org/10.21037/apm-20-2275). The authors have no conflicts of interest to declare.

Ethical Statement: The authors are accountable for all aspects of the work in ensuring that questions related to the accuracy or integrity of any part of the work are appropriately investigated and resolved. Written informed consent was obtained from the patient for publication of this study and any accompanying images. All procedures performed in studies involving human participants were in accordance with the ethical standards of the institutional and/or national research committee(s) and with the Helsinki Declaration (as revised in 2013).

Open Access Statement: This is an Open Access article distributed in accordance with the Creative Commons Attribution-NonCommercial-NoDerivs 4.0 International License (CC BY-NC-ND 4.0), which permits the noncommercial replication and distribution of the article with the strict proviso that no changes or edits are made and the original work is properly cited (including links to both the formal publication through the relevant DOI and the license). See: https://creativecommons.org/licenses/by-nc-nd/4.0/.

\section{References}

1. Christopherson WM, Foote FW Jr, Stewart FW. Alveolar 
soft-part sarcomas; structurally characteristic tumors of uncertain histogenesis. Cancer 1952;5:100-11.

2. Goldblum JR FA, Weiss SW, Enzinger FM, et al. Enzinger and Weiss's soft tissue tumors. Philadelphia, PA: Elsevier Publishing Company; 2014.

3. Sood N, Gulia M. Alveolar soft part sarcoma: A case report with emphasis on some unusual cytological features. Diagn Cytopathol 2018;46:170-4.

4. Kayton ML, Meyers P, Wexler LH, et al. Clinical presentation, treatment, and outcome of alveolar soft part sarcoma in children, adolescents, and young adults. J Pediatr Surg 2006;41:187-93.

5. Groisberg R, Hong DS, Behrang A, et al. Characteristics and outcomes of patients with advanced sarcoma enrolled in early phase immunotherapy trials. J Immunother Cancer 2017;5:100.

6. Lewin J, Davidson S, Anderson ND, et al. Response to Immune Checkpoint Inhibition in Two Patients with Alveolar Soft-Part Sarcoma. Cancer Immunol Res 2018;6:1001-7.

7. Wang G, Sun M, Jiang Y, et al. Anlotinib, a novel small molecular tyrosine kinase inhibitor, suppresses growth and metastasis via dual blockade of VEGFR2 and MET in osteosarcoma. Int J Cancer 2019;145:979-93. Anlotinib, a novel small molecular tyrosine kinase inhibitor, suppresses growth and metastasis via dual blockade of VEGFR2 and MET in osteosarcoma. Int J Cancer 2019;145:979-93.

8. Xu J, Zhang Y, Jia R, et al. Anti-PD-1 Antibody SHR-1210 Combined with Apatinib for Advanced Hepatocellular Carcinoma, Gastric, or Esophagogastric Junction Cancer: An Open-label, Dose Escalation and Expansion Study. Clin Cancer Res 2019;25:515-23.

9. Fang W, Yang Y, Ma Y, et al. Camrelizumab (SHR-1210) alone or in combination with gemcitabine plus cisplatin for nasopharyngeal carcinoma: results from two single-arm, phase 1 trials. Lancet Oncol 2018;19:1338-50.

10. Conley AP, Trinh VA, Zobniw CM, et al. Positive Tumor Response to Combined Checkpoint Inhibitors in a Patient With Refractory Alveolar Soft Part Sarcoma: A Case Report. J Glob Oncol 2018;4:1-6.

11. Ogose A, Yazawa Y, Ueda T, et al. Alveolar soft part sarcoma in Japan: multi-institutional study of 57 patients from the Japanese Musculoskeletal Oncology Group. Oncology 2003;65:7-13.

12. Bychkov A, Sampatanukul P. Alveolar soft part sarcoma presenting as a breast metastasis in a patient with a history of thyroid cancer: a case report. Int J Clin Exp Pathol 2015;8:9731-6.
13. Lindberg MR. Diagnostic Pathology: Soft Tissue Tumors nEP, PA: Elsevier Publishing Company, 2015:678-81.

14. López-Ferrer P, Jiménez-Heffernan JA, Vicandi B, et al. Cytologic features of alveolar soft part sarcoma: report of three cases. Diagn Cytopathol 2002;27:115-9.

15. Majumdar K, Saran R, Tyagi I, et al. Cytodiagnosis of alveolar soft part sarcoma: Report of two cases with special emphasis on the first orbital lesion diagnosed by aspiration cytology. J Cytol 2013;30:58-61.

16. Price RL, Harkins L, Chiocca EA, et al. Human Cytomegalovirus is Present in Alveolar Soft Part Sarcoma. Appl Immunohistochem Mol Morphol 2017;25:615-9.

17. Jour G,Hoch BL,Oda D, et al. Metastatic alveolar soft part sarcoma to the posterior mandible as initial presentation: a first report of an extremely uncommon scenario. J Oral Maxillofac Surg Med Pathol 2015;27:438-41.

18. Argani P,Lal P,Hutchinson B,et al. Aberrant nuclear immunoreactivity for TFE3 in neoplasms with TFE3 gene fusions: a sensitive and specific immunohistochemical assay. Am J Surg Pathol 2003;27:750-61.

19. Portera CA Jr, Ho V, Patel SR, et al. Alveolar soft part sarcoma: clinical course and patterns of metastasis in 70 patients treated at a single institution. Cancer 2001;91:585-91.

20. GT Clifton,EA Mittendorf,GE Peoples.Overcoming cancer tolerance with Immune checkpoint blockade. In:Rezaei, Nima, editors. Cancer Immunology Bench to Bedside Immunotherapy of Cancers. Springer Berlin Heidelberg 2015;104-8.

21. Butterfield,Lisa H HL, Kaufman, et al. Cancer Immunotherapy Principles and Practice. New York: Demos Medical Publishing. 2017.

22. Wang SD, Li HY, Li BH, et al. The role of CTLA-4 and PD-1 in anti-tumor immune response and their potential efficacy against osteosarcoma. Int Immunopharmacol 2016;38:81-9.

23. Callahan MK, Wolchok JD. At the bedside: CTLA-4- and PD-1-blocking antibodies in cancer immunotherapy. J Leukoc Biol 2013;94:41-53.

24. Huang J, Xu B, Mo H, et al. Safety, Activity, and Biomarkers of SHR-1210, an Anti-PD-1 Antibody, for Patients with Advanced Esophageal Carcinoma. Clin Cancer Res 2018;24:1296-304.

25. Conry A, Peters M, Fried DB, et al. Complete Response to Dual Immunotherapy in a Young Adult with Metastatic Alveolar Soft Part Sarcoma Enabled by a Drug Recovery Program in a Community Practice. J Adolesc Young Adult Oncol 2020;9:449-52. 
26. Markham A, Keam SJ.Camrelizumab: First Global Approval.Drugs 2019;79:1355-61.

27. Tawbi HA, Burgess M, Bolejack V, et al. Pembrolizumab in advanced soft-tissue sarcoma and bone sarcoma (SARC028): a multicentre, two-cohort, single-arm, openlabel, phase 2 trial. Lancet Oncol 2017;18:1493-501.

28. Weber JS YJ,Atkins MB,Disis ML. Toxicities of Immunotherapy for the Practitioner. J Clin Oncol 2015;33:2092-9.

29. Lan C, Shen J, Wang Y, et al. Camrelizumab Plus Apatinib in Patients With Advanced Cervical Cancer (CLAP): A Multicenter, Open-Label, Single-Arm, Phase II Trial. J Clin Oncol 2020;38):4095-106.

30. Ren C, Mai ZJ, Jin Y, et al. Anti-PD-1 antibody SHR1210 plus apatinib for metastatic colorectal cancer: a prospective, single-arm, open-label, phase II trial. Am J Cancer Res 2020;10:2946-54.

Cite this article as: $\mathrm{Xu} \mathrm{Z,} \mathrm{Zhang} \mathrm{Y,} \mathrm{Yu} \mathrm{YH.} \mathrm{Successful}$ treatment of advanced alveolar soft part sarcoma with camrelizumab combined with apatinib: a case report. Ann Palliat Med 2021;10(1):785-792. doi: 10.21037/apm-20-2275
31. Fan Y, Zhao J, Wang Q, et al. Camrelizumab Plus Apatinib in Extensive-Stage Small-Cell Lung Cancer (PASSION): A Multicenter, Two-Stage, Phase 2 Trial. J Thorac Oncol 2020. [Epub ahead of print]. doi: 10.1016/ j.jtho.2020.10.002.

32. Xu J, Shen J, Gu S, et al. Camrelizumab in combination with apatinib in patients with advanced hepatocellular carcinoma (RESCUE): a non-randomized, open-label, phase 2 trial. Clin Cancer Res 2020. [Epub ahead of print]. doi: 10.1158/1078-0432.CCR-20-2571.

33. Li W, Wei Z, Yang X, et al. Salvage therapy of reactive capillary hemangiomas: Apatinib alleviates the unique adverse events induced by camrelizumab in non-small cell lung cancer. J Cancer Res Ther 2019;15:1624-8.

(English Language Editors: J. Teoh and J. Reynolds) 